\title{
LA LUCHA CONTRA LA DISCRIMINACIÓN EN EL ACCESO AL EMPLEO MEDIANTE EL CURRÍCULUM VITAE ANÓNIMO ${ }^{1}$
}

\author{
Antonio Fernández García ${ }^{2}$ \\ Profesor Lector de Derecho del Trabajo y de la Seguridad Social \\ Universitat Oberta de Catalunya (UOC)
}

\begin{abstract}
Este trabajo analiza la eficacia del currículum vitae anónimo o ciego (CVA) en la lucha contra la discriminación en el acceso al empleo. El CVA tiene como finalidad evitar sesgos discriminatorios de género en los procesos de selección de personal En primer lugar, ofrecemos unos breves apuntes sobre el estado de la normativa relativa a la discriminación en los procesos de selección de personal y las formas de tutela contra la misma. En segundo lugar, examinamos una iniciativa institucional para promover el CVA así como la forma de implantarlo en una empresa adecuándolo a la normativa antidiscriminatoria. Analizamos las características tecnológicas y técnico-jurídicas que debe tener el CVA para resultar efectivo, tanto para evitar la discriminación de género como otras discriminaciones. Finalmente, desarticularemos con nuestro argumentario una de las críticas más destacadas a esta herramienta.
\end{abstract}

This paper analyses the efficiency of the Anonymous or Blind Curriculum Vitae (ACV) as a measure to counter discrimination in the selection process for a job vacancy. The $A C V$ aims at removing any gender bias or discrimination in recruitment procedures. First, this paper describes the current legal framework on protection against discrimination in selection processes. Second, it examines an institutional initiative to promote the ACV as well as its implementation into a company respecting the current legislation against labour discrimination. Eventually, the paper explores the technological and techno-juridical aspects involving a recruitment process based on $A C V$ to effectively remove gender discrimination from the equation, as well as any other type of bias. Eventually, the analysis disputes the most common criticism against ACV.

\footnotetext{
${ }^{1}$ Parte de las ideas desarrolladas en este trabajo se derivan de la comunicación presentada al 2nd SBRLab International Virtual Conference (12-14 de diciembre de 2018, Tarragona) con el título "El proyecto de currículum vitae anónimo: breve análisis para el debate". El autor quiere agradecer a Elena López y Mikel Solaun del departamento de Culture and People de IKEA Ibérica S.A. la información suministrada para enriquecer este trabajo.

2 ORCID ID: 0000-0003-1382-4407. El autor es miembro del grupo de investigación consolidado reconocido por la Generalitat de Catalunya "Fiscalidad, relaciones laborales y empresa". Ref. 2017 SGR 258.
} 
IUSLabor 1/2019, ISSN 1699-2938, p. 233-266

DOI. 10.31009/IUSLabor.2019.i01.05

Title: The fight against the access to the employment discrimination's using the Anonymous Curriculum Vitae

Palabras clave: currículum vitae anónimo, derecho a la no discriminación, selección de personal.

Keywords: Anonymous Curriculum Vitae, right to non-discrimination, recruitment.

\section{Sumario}

1. Introducción

2. La normativa sobre discriminación en los procesos de selección de personal

3. El currículum vitae anónimo (CVA)

4. La implantación de un sistema efectivo de CVA en la lucha contra la discriminación

4.1 Tecnología y CVA

4.2 Diseño técnico-jurídico del proceso

4.3 Política de empresa alineada con la igualdad

5. La prueba de la discriminación y el CVA

6. Conclusiones

7. Bibliografía 


\section{Introducción}

El último Eurobarómetro sobre la discriminación en la UE ofrece interesantes datos relativos a la discriminación a la hora de acceder a un puesto de trabajo ${ }^{3}$. Un $67 \%$ de los encuestados españoles cree que un candidato con más de 55 años está en situación de desventaja frente a otro candidato de menor edad a la hora de ser contratado por una empresa pese a tener ambos las mismas habilidades y cualificaciones. Si el candidato tiene menos de 30 años solo lo consideran en desventaja un $21 \%$ de los encuestados. El porcentaje alcanza el $47 \%$ en caso de candidatos con discapacidad, el $45 \%$ cuando se habla del color de piel u origen étnico del candidato, el $44 \%$ en relación con la identidad de género (ser transgénero o transexual) y el $31 \%$ si la persona es gay, lesbiana o bisexual. Expresar una creencia religiosa supone una desventaja para el $27 \%$ de los encuestados españoles y el género del candidato lo supone para el $29 \%$.

Por su parte, en el estudio Los perfiles de la discriminación en España se estima que un $13,3 \%$ de la población encuestada no ha sido contratada por motivos discriminatorios ${ }^{4}$, destacándose como motivos de ese trato peyorativo el sexo (en concreto, ser mujer), la edad (en concreto, ser joven), el origen étnico o la nacionalidad ${ }^{5}$.

Nótese que hasta el momento nos estamos refiriendo a factores expresamente tasados por la diferente normativa antidiscriminatoria y que corresponden a colectivos históricamente perjudicados. Pero nos interesa también señalar otros motivos de desventaja a la hora de participar en un proceso de selección de personal. Así, el Eurobarómetro indica que el $59 \%$ de los encuestados españoles considera que la manera de vestir o presentarse de un candidato puede ponerle en desventaja durante un proceso de selección. El porcentaje desciende hasta el $49 \%$ al centrarnos en el aspecto físico general del candidato (altura, peso, cara), hasta el $23 \%$ al referirnos a su forma de hablar (acento) y hasta el $8 \%$ en cuanto al nombre y la dirección del candidato. No es difícil argumentar que algunos de esos factores van ligados a la nacionalidad o al origen étnico. Asimismo, el trato desigual motivado por el aspecto físico también va asociado a cánones de belleza donde confluyen el sexo, la edad, el sobrepeso, la obesidad,

\footnotetext{
${ }^{3}$ COMISIÓN EUROPEA, Eurobarómetro La discriminación en la UE en 2015. Resultados en España, [en línea] [fecha de consulta 28/11/2018], disponible en:

http://ec.europa.eu/COMMFrontOffice/publicopinion/index.cfm/Survey/getSurveyDetail/instruments/SP ECIAL/surveyKy/2077.

${ }^{4}$ ALter, Los perfiles de la discriminación en España: Análisis de la Encuesta CIS-3.000 Percepción de la discriminación en España, Ministerio de Sanidad, Servicios Sociales e Igualdad, Madrid, 2014, p. 140.

${ }^{5}$ ALTER, Los perfiles de la discriminación en España..., op. cit., p. 141.
} 
determinadas discapacidades ${ }^{6}$ y la vestimenta ligada a la falta recursos económicos de la persona $^{7}$ o a sus creencias religiosas ${ }^{8}$.

Lo que pretendemos indicar con estos datos es que existe una discriminación en el acceso al empleo basada de forma consciente en una voluntad del empresario de no contratar a determinados colectivos pero que también puede darse de forma involuntaria por sesgos inconscientes. Se ha comprobado que, ante idénticos currículum vitae donde solo cambiaba el sexo del candidato, se ha valorado menos al que correspondía a una mujer ${ }^{9}$. Dichos sesgos de género se generalizan cuando nos encontramos ante puestos de trabajo con mayor proporción de trabajadores hombres que de mujeres (maledominated jobs), por lo que aumenta la posibilidad de que se contrate antes a un candidato que a una candidata para cubrirlos ${ }^{10}$. También se ha demostrado que los currículums vitae de personas que llevan tiempo desempleadas tienen más posibilidades de ser descartados por ese único factor ${ }^{11}$. De ahí que el uso de currículum vitae con datos estrictamente profesionales se plantee como solución para evitar esas discriminaciones involuntarias basadas en sesgos del seleccionador que impiden que los postulantes superen la primera fase de los procesos selectivos. Estamos hablando del currículum vitae anónimo o ciego (en adelante, CVA) que, al igual que el método de las "audiciones ciegas" en la selección de músicos de orquesta ${ }^{12}$, ayuda a prevenir las discriminaciones involuntarias y las órdenes conscientes de discriminar emitidas por determinados empresarios.

\footnotetext{
${ }^{6}$ Álvarez Del Cuvillo, A., "Aspecto del trabajador y prohibición de discriminación", Trabajo y Derecho, 2015, nº 10, p. 78.

${ }^{7}$ ALTER, Los perfiles de la discriminación en España..., op. cit., p. 111-112.

${ }^{8}$ Sobre el uso de velo islámico y la imagen personal en el trabajo puede verse PURCALLA BonILLA, M. A., "Velo islámico y empleo por cuenta ajena", Blog AFLabor [en línea] [fecha de consulta 28/11/2018], disponible en: https://aflabor.wordpress.com/2017/03/28/velo-islamico-y-empleo-por-cuenta-ajenacolaboracion-de-miquel-angel-purcalla-bonilla/.

${ }^{9}$ Moss-Racusin, C. A., Dovidio, J. F., Brescoll, V. L., Graham, M. J. y Handelsman, J., "Science faculty's subtle gender biases favor male students", Proceedings of the National Academy of Sciences, vol. 109, no 41, 2012, p. 16474-16479, disponible en: https://doi.org/10.1073/pnas.1211286109.

${ }^{10}$ Koch, A. J., D'MeLlO, S. D., y SACKETT, P. R., “A meta-analysis of gender stereotypes and bias in experimental simulations of employment decision making", Journal of Applied Psychology, $\mathrm{n}^{\circ}$ 100, 2015, p. 128-161, Disponible en: http://dx.doi.org/10.1037/a0036734.

${ }^{11}$ GHAYAD, R. y DiCKENS, W. T., "What Can We Learn by Disaggregating the Unemployment-Vacancy Relationship?", FRB of Boston Public Policy Brief, 2012, $\mathrm{n}^{\circ}$ 12-3, disponible en: https://papers.ssrn.com/sol3/papers.cfm?abstract_id=2285075.

${ }^{12}$ Los evaluadores juzgan únicamente la música que escuchan sin ver a la persona que la ejecuta por lo que se eliminan sesgos discriminatorios, especialmente por razón de sexo, Goldin, C. y RouSE, C., "Orchestrating Impartiality: The Impact of 'Blind' Auditions on Female Musicians", American Economic Review, vol. 90, $\mathrm{n}^{\circ}$ 4, 2000, p. 715-741, disponible en: DOI: 10.1257/aer.90.4.715.
} 
Este trabajo pretende analizar la eficacia del CVA en la lucha contra la discriminación en el acceso al empleo en el sector privado. En primer lugar, ofreceremos unos breves apuntes sobre el estado de la normativa relativa a la discriminación en los procesos de selección de personal y las formas de tutela contra la misma. Analizaremos una iniciativa institucional para promover el CVA, así como la forma de implantarlo en una empresa adecuándolo a la normativa antidiscriminatoria. Finalmente, desarticularemos con nuestro argumentario una de las críticas más destacadas a esta herramienta.

\section{La normativa sobre discriminación en los procesos de selección de personal}

La discriminación en los procesos de selección de personal se produce en el momento del acceso al empleo, esto es, en las diversas fases precontractuales o de colocación como pueden ser la intermediación laboral, la emisión y difusión de una oferta de empleo, las entrevistas y otras pruebas selectivas, la negociación previa a la contratación, etc. Estos momentos previos a la celebración de un contrato de trabajo se caracterizan por una escasa regulación primando así el derecho a la libertad de empresa (artículo 38 Constitución Española, en adelante CE) para seleccionar y contratar a los trabajadores que se considere más adecuados (STC 147/1986, de 25 de noviembre). Dicha libertad del empresario queda únicamente sujeta a unos límites marcados especialmente por los diferentes derechos constitucionales, entre los que destaca el derecho a no sufrir discriminaciones, reconocido en el artículo $14 \mathrm{CE}$, en el artículo 5 de la Ley Orgánica 3/2007, de 22 de marzo, para la igualdad efectiva de mujeres y hombres (en adelante, LOI), en los artículos 4.2 c) y 17.1 del RD Legislativo 2/2015, de 23 de octubre, por el que se aprueba el texto refundido de la Ley del Estatuto de los Trabajadores (en adelante, ET) y en el artículo 34 y siguientes de la Ley 62/2003, de 30 de diciembre, de medidas fiscales, administrativas y del orden social.

Asimismo, proscribe la discriminación durante el acceso al empleo diferente normativa comunitaria, a saber: la Directiva 2006/54/CE, de 5 de julio, sobre aplicación del principio de igualdad de oportunidades e igualdad de trato entre hombres y mujeres en asuntos de empleo y ocupación ${ }^{13}$; la Directiva 2000/78/CE, de 27 de noviembre, relativa al establecimiento de un marco general para la igualdad de trato en el empleo y la ocupación (religión, convicciones, discapacidad, edad y orientación sexual); $\mathrm{y}$, finalmente, la Directiva 2000/43/CE, de 29 de junio, sobre aplicación del principio de igualdad de trato a las personas independientemente de su origen racial o étnico.

Nuestro Alto Tribunal ha definido la discriminación como una conducta que "se cualifica por el resultado peyorativo para el sujeto que la sufre, que ve limitados sus

\footnotetext{
${ }^{13}$ Véase también la STJCE de 21 de mayo de 1985, C-248/83, asunto Comisión contra República Federal de Alemania.
} 
derechos o sus legítimas expectativas por la concurrencia en él de un factor cuya virtualidad justificativa ha sido expresamente descartada por la Constitución, por su carácter atentatorio a la dignidad del ser humano (artículo 10.1 CE)" (STC 173/1994, de 7 de junio). La discriminación en un proceso de selección puede ser directa o indirecta. La primera se materializa en una diferencia de trato intencionada que origina un perjuicio y cuya única justificación es la circunstancia o factor personal o social del candidato. Se habla de discriminación directa abierta cuando esta es perceptible en un conocimiento superficial de la situación. Por ejemplo, cuando un empleador declara públicamente que no contrata a homosexuales (STJUE de 25 de abril de 2013, C-81/12, asunto Asociaţia Accept), extranjeros o personas de determinado origen racial o étnico porque a sus clientes no les agrada este perfil de trabajador (STJUE de 10 de julio de 2008, C-54/07, asunto Feryn). Como es de suponer, en multitud de ocasiones la actitud discriminatoria suele ser más velada, hablándose entonces de discriminación directa oculta o encubierta. En estos casos, la causa determinante del tratamiento peyorativo sigue siendo una de las prohibidas, solo que se ha tratado de esconder bajo denominaciones o instituciones en los que la trascendencia de dicho factor es secundaria o no es en absoluto evidente ${ }^{14}$. El ejemplo sería el de descartar a un candidato en una entrevista de selección alegando falta de experiencia profesional cuando en realidad se le está descartando por pertenecer a una determinada etnia, por su sexo, estado de embarazo, edad, etc.

Por su parte, la discriminación indirecta la constituye "toda disposición normativa heterónoma, cláusula convencional o contractual, pacto individual o decisión unilateral que, aparentemente neutra, ocasione una desventaja particular a una persona respecto de otras por las referidas razones, siempre que objetivamente no respondan a una finalidad legítima y que los medios para su consecución no sean adecuados y necesarios" (STSJ Cantabria de 14 de noviembre de 2005, rec. no 905/2005).

Debe tenerse en cuenta que la jurisprudencia comunitaria ha ido ampliando el concepto de discriminación por razón de sexo, de discapacidad y de origen étnico. Así, el concepto de discriminación se ha ampliado a la derivada del embarazo, la maternidad, la asunción de obligaciones familiares y el estado civil (artículo 3 y 8 LOI). Por otro lado, la protección frente al trato peyorativo discriminatorio se extiende a los familiares de las personas con discapacidad (STJUE de 17 de julio de 2008, C-303/06, asunto Coleman) $\mathrm{y}$ a personas afectadas por decisiones discriminatorias basadas en motivos étnicos pese a no pertenecer a la etnia en cuestión (STJUE de 16 de julio de 2015, C-83/14, asunto CHEZ Razpredelenie Bulgaria AD).

\footnotetext{
${ }^{14}$ PÉREZ DEL Río, T., "El principio de igualdad de trato y la prohibición de discriminación por razón de sexo en el derecho Comunitario", en RuIz PéRez, E. (Coordinadora), Mujer y trabajo, Bomarzo, Albacete, 2003, p. 287.
} 
Por lo tanto, se entiende que una persona ha sido discriminada en el acceso a un empleo cuando se la ha excluido durante cualquiera de las fases previas a la contratación por la concurrencia en ella de alguno de los factores tasados en la legislación sin que exista una justificación amparada por la misma. Dichas justificaciones aparecen en diversos preceptos normativos. Por ejemplo, en relación al factor sexo, el artículo 5 LOI establece que "no constituirá discriminación en el acceso al empleo, incluida la formación necesaria, una diferencia de trato basada en una característica relacionada con el sexo cuando, debido a la naturaleza de las actividades profesionales concretas o al contexto en el que se lleven a cabo, dicha característica constituya un requisito profesional esencial y determinante, siempre y cuando el objetivo sea legítimo y el requisito proporcionado". En similares términos se expresa el artículo 4 Directiva 2000/78/CE respecto a una diferencia de trato basada en una característica relacionada con la religión, las convicciones, la discapacidad, la edad y la orientación sexual. En el caso de la edad, el artículo 6 de la mencionada Directiva indica que las diferencias de trato admitidas pueden incluir: el establecimiento de condiciones especiales de acceso al empleo para los jóvenes, los trabajadores de mayor edad y los que tengan personas a su cargo, con vistas a favorecer su inserción profesional o garantizar la protección de dichas personas ${ }^{15}$; el establecimiento de condiciones mínimas en lo que se refiere a la edad para acceder al empleo o a determinadas ventajas vinculadas al mismo; y, el establecimiento de una edad máxima para la contratación, que esté basada en los requisitos de formación del puesto en cuestión o en la necesidad de un período de actividad razonable previo a la jubilación ${ }^{16}$.

En este punto debe recordarse que existe posibilidad de establecer medidas de acción positiva, tanto de origen estatal como convencional. En el acceso al empleo son destacables las relacionadas con el factor sexo que se establecen "en favor de las mujeres para corregir situaciones patentes de desigualdad de hecho respecto de los hombres" que tendrán una duración temporal mientras subsistan dichas situaciones y deberán ser "razonables y proporcionadas en relación con el objetivo perseguido en cada caso" (artículo 11 LOI). En similar sentido se expresa el artículo 17 ET al permitir que puedan establecerse por ley "las exclusiones, reservas y preferencias para ser contratado libremente" y puedan regularse "medidas de reserva, duración o preferencia en el empleo que tengan por objeto facilitar la colocación de trabajadores demandantes de empleo". También previa consulta con las organizaciones empresariales y sindicales más representativas podrán otorgarse "subvenciones, desgravaciones y otras medidas

\footnotetext{
${ }^{15}$ Por ejemplo, la STJUE de 19 de julio de 2017, C-143/16, asunto Abercrombie \& Fitch Italia.

${ }^{16}$ Este último sería el caso de la STS de 30 de mayo de 2012 (rec. n n $^{\circ}$ 63/2010) que no considera discriminatoria la edad máxima de acceso establecida para el personal de tropa y marinería de las Fuerzas Armadas.
} 
para fomentar el empleo de grupos específicos de trabajadores que encuentren dificultades especiales para acceder al empleo". Conforman ejemplos de estas medidas la cuota de reserva de puestos de trabajo para personas con discapacidad ${ }^{17}$ o los diversos incentivos económicos a la contratación de trabajadores mayores de 52 años ${ }^{18}$, jóvenes menores de 25 años $^{19}$, personas con discapacidad ${ }^{20}$, etc.

Por su parte, las medidas de acción positiva que pueden implantarse mediante la negociación colectiva son las referidas a "favorecer el acceso de las mujeres al empleo y la aplicación efectiva del principio de igualdad de trato y no discriminación en las condiciones de trabajo entre mujeres y hombres" (artículo 43 LOI). El artículo 17.4 ET habla de "favorecer el acceso de las mujeres a todas las profesiones" para lo que permite negociar el establecimiento de "reservas y preferencias en las condiciones de contratación de modo que, en igualdad de condiciones de idoneidad, tengan preferencia para ser contratadas las personas del sexo menos representado en el grupo profesional de que se trate". En relación con esta cuestión, sería oportuno que la legislación abordase la definición de este concepto de sexo menos representado o subrepresentado $^{21}$.

Las pocas disposiciones normativas que establecen obligaciones específicas relacionadas con los procesos de selección de personal son las que se refieren a las infracciones administrativas por publicar ofertas de empleo discriminatorias (artículos 15.5 y 16.2 del Real Decreto Legislativo 5/2000, de 4 de agosto, por el que se aprueba el texto refundido de la Ley sobre Infracciones y Sanciones en el Orden Social). También el Real Decreto Legislativo 3/2015, de 23 de octubre por el que se aprueba el texto refundido de la Ley de Empleo (en adelante, LE) considera discriminatorias "las ofertas referidas a uno de los sexos, salvo que se trate de un requisito profesional esencial y determinante de la actividad a desarrollar" y siempre se "considerará discriminatoria la oferta referida a uno solo de los sexos basada en exigencias del puesto de trabajo relacionadas con el esfuerzo físico" (artículo 35.2 LE) ${ }^{22}$.

\footnotetext{
${ }^{17}$ Artículo 42 Real Decreto Legislativo 1/2013, de 29 de noviembre, por el que se aprueba el Texto Refundido de la Ley General de derechos de las personas con discapacidad y de su inclusión social.

${ }^{18}$ Ley 45/2002, de 12 de diciembre, de medidas urgentes para la reforma del sistema de protección por desempleo y mejora de la ocupabilidad.

${ }^{19}$ Artículo 3 Ley 3/2012, de 6 de julio, de medidas urgentes para la reforma del mercado laboral.

${ }^{20}$ Entre otros, los incentivos previstos en la Ley 43/2006, de 29 de diciembre, para la mejora del crecimiento y del empleo.

${ }^{21}$ SIERRA HERNÁIz, E., "El papel de los planes de igualdad en la implantación de medidas de igualdad efectiva en las empresas", Lan Harremanak: Revista de relaciones laborales, 2017, n 38, p. 226.

${ }^{22}$ Anuncios que contengan diversas menciones y referencias al sexo masculino sin que se expresen unas condiciones para el desempeño del trabajo que justifiquen la exclusión de las mujeres para el puesto de trabajo descrito, caso de la STSJ de Cataluña de 10 de octubre de 2005 (rec. n $^{\circ}$ 476/2000) o el ejemplo
} 
Tras lo expuesto, queda claro que el legislador ha dejado la regulación de los procesos de selección de personal al ámbito de la negociación colectiva ${ }^{23}$. No puede hablarse de éxito en esta materia pues pocos convenios introducen mecanismos efectivos de erradicación de conductas discriminatorias y menos aún de medidas de acción positiva. Se viene a perpetuar la tendencia clásica, es decir, la exigua regulación del ingreso al trabajo con el consiguiente elevado margen de discrecionalidad empresarial ${ }^{24}$. En ese sentido, una de las manifestaciones de la negociación colectiva como son los planes de igualdad (Capítulo III de la LOI), también pueden incluir medidas tendentes a evitar la discriminación en el acceso al empleo, si bien específicamente referidas al factor sexo ${ }^{25}$. Abordaremos está cuestión con más detalle en un próximo epígrafe.

Finalmente, respecto a la tutela judicial, está prevista la modalidad procesal de tutela de derechos fundamentales (artículo 177 y siguientes de la Ley 36/2011, de 10 de octubre, reguladora de la jurisdicción social, en adelante, LRJS) frente al empresario discriminador y terceros vinculados (empresas de selección de personal, por ejemplo) donde intervendrá también el Ministerio Fiscal (artículo 177.3 LRJS) y se tramitará con carácter de urgente (artículo 179.1 LRJS). Pueden actuar como coadyuvantes los sindicatos más representativos y las entidades públicas o privadas entre cuyos fines se encuentre la promoción y defensa de los intereses legítimos afectados, si bien no podrán personarse, recurrir ni continuar el proceso contra la voluntad del candidato perjudicado (artículo 177.2 LRJS) ${ }^{26}$. El tema de la prueba y de las posibles indemnizaciones lo trataremos más adelante.

extraído de la STJUE de 22 de abril de 1997, C-180/95, asunto Draehmpaehl: "buscamos para nuestra empresa de distribución una colaboradora de la Dirección con experiencia".

${ }^{23}$ Una extensa enumeración de cláusulas convencionales sobre selección de personal puede verse en Alameda Castillo, M. T., Estadios previos al contrato de trabajo y discriminación, Thomson Reuters Aranzadi, Cizur Menor (Navarra), 2014, p. 196 y en diferentes capítulos de SÁNCHEZ TriguEROS, C. (Directora), KAHAle CARrillo, D. T. y Velasco Portero, T. (Coordinadores), El principio de igualdad en la negociación colectiva, Ministerio de Empleo y Seguridad Social, Madrid, 2016.

${ }^{24}$ Fernández García, A. y UReña Martín, A., "La igualdad en el acceso al empleo, la clasificación, la formación y la promoción profesional" en ROMERo BuRILlo, A. M. y RODRíGUEZ ORDAZ, C. (Coordinadoras), Trabajo, género e igualdad, Thomson Reuters Aranzadi, Cizur Menor (Navarra), 2018, p. 59.

${ }^{25}$ Martínez Miranda, M.M., "Los retos de los principios esenciales del Derecho del Trabajo: El principio de igualdad", XXVII Jornadas Catalanas de Derecho Social, Barcelona, 17 y 18 de marzo de 2016, p. 7, disponible en: http://www.iuslabor.org/jornades-i-seminaris/ponencies/any-2016/.

${ }^{26} \mathrm{La}$ ventaja de dicha participación como coadyuvantes es que pueden dar una notable difusión a través de sus redes sociales. La denuncia social y la repercusión mediática que la reprobación de dichos organismos públicos o privados puede tener, puede ser un paso muy importante a la hora de conseguir la efectividad de la tutela a través de esta modalidad procesal, ChaCARTEGUI Jávega, C., "Incidencia de nuevas TIC en la intermediación privada, el problema de la utilización de plataformas electrónicas para 
En resumen, disponemos de normativa que proscribe de forma general la discriminación en el acceso al empleo y que deja la regulación específica en manos de la negociación colectiva. La vía administrativa de tutela se centra en sancionar las conductas empresariales discriminatorias incluyendo la publicación y difusión de ofertas de empleo con esas características. Se prevé también una modalidad procesal específica a la que puede acudir el candidato que considere vulnerado su derecho a no ser discriminado durante un proceso de selección de personal. Se conforman así dos grupos de medidas: unas de tipo preventivo y otras reparadoras del daño causado.

\section{El currículum vitae anónimo (CVA)}

En 2017, la implantación del CVA en las empresas españolas fue propuesta por el Ministerio de Sanidad, Servicios Sociales e Igualdad (actual Ministerio de Sanidad, Consumo y Bienestar Social), a través del Instituto de la Mujer y para la Igualdad de Oportunidades. El "Protocolo general para el diseño, implantación y valoración de un proyecto de currículum vitae anónimo para la selección de personal" se anunció como un proyecto en el que podían participar las empresas y entidades que celebrasen un

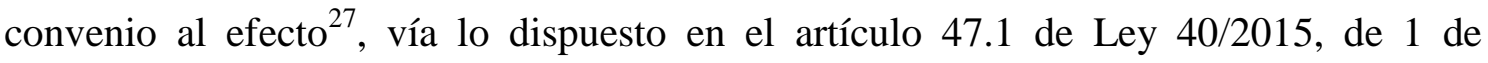
octubre, de Régimen Jurídico del Sector Público. En dicho convenio intervienen, por un lado, la Secretaría de Estado de Servicios Sociales e Igualdad y por el otro "empresas y otras entidades que participan activamente en los procesos de selección de personal", incluyendo "agentes sociales, universidades, escuelas de negocio, colegios profesionales, empresas de selección de talento" (cláusula cuarta del Protocolo general).

Hasta la fecha se han adherido a este proyecto 92 entidades: empresas privadas (banca, seguros, consultoría, alimentación, telecomunicaciones, abogacía, energía, construcción, automoción, etc.), asociaciones, fundaciones, sindicatos (CCOO, UGT, FETICO), empresas de trabajo temporal (Randstad, Selección Selectiva ETT, Synergie), un portal de empleo (Infojobs), un ayuntamiento (Alcorcón), una cámara de comercio (Huesca) y una universidad (Universitat Politècnica de València) ${ }^{28}$.

Estaba previsto que estas entidades se organizaran a través de grupos de trabajo para diseñar, teniendo en cuenta sus características, tamaño, sector y particularidades, los

eludir derechos", XXIX Jornadas Catalanas de Derecho Social, Barcelona, 8 y 9 de marzo de 2018, p. 19, disponible en: http://www.iuslabor.org/jornades-i-seminaris/ponencies/any-2018/.

${ }^{27}$ Modelo de protocolo [en línea] [fecha de consulta 30/11/2018], disponible en: http://www.igualdadenlaempresa.es/novedades/noticias/docs/Protocolo_cv_anonimo.pdf.

${ }^{28}$ Listado de entidades [en línea] [fecha de consulta 30/11/2018], disponible en: https://www.mscbs.gob.es/ssi/igualdadOportunidades/iEmpleo/cvanonimo/cvanonimol.htm. 
procedimientos y modelos más adecuados para facilitar la implantación del CVA; las fases del proceso de selección en los que cabe implantarlo; la forma de implantación y los indicadores estadísticos que deberán recoger las empresas para poder evaluar la efectividad del mismo, así como recomendaciones para la mejora del proyecto. Estos grupos de trabajo estarían formados por representantes de la Secretaría de Estado de Servicios Sociales e Igualdad y por representantes de las empresas y entidades interesadas. Los primeros se encargarían de coordinarlos y dinamizarlos y los segundos participarían en el grupo que les corresponda en función de sus características. También se preveía la posibilidad de participación de "personas expertas en materia de selección de personal sin sesgos de género, a petición de cualquiera de las partes" y se indicó que se salvaguardaba la libertad de las entidades firmantes para promover, impulsar e implantar las medidas de acción positiva que considerasen más adecuadas para facilitar la participación equilibrada de mujeres y hombres en los distintos niveles y ámbitos de su organización. Parece ser que, tras una primera reunión informativa donde se agrupó a las entidades de la forma mencionada, se decidió que cada entidad pudiera actuar de forma autónoma y con total libertad a la hora de implantar el CVA, aunque debería ser capaz de medir los resultados del proyecto y enviarlos al Ministerio dos veces al año.

A nuestro entender, esta decisión fue un acierto puesto que la metodología basada en grupos de trabajo podría haber complicado los avances. Según el modelo de Protocolo, el proyecto se define como "flexible, abierto y dinámico" y puede implantarse en su totalidad o en parte además de poder acordarse cuantas modificaciones se consideren oportunas para mejorar su desarrollo. El proyecto tiene una duración de 24 meses pudiendo prorrogarse de forma expresa en cualquier momento antes de su finalización. Cabe resolución por mutuo acuerdo entre las partes o denuncia con tres meses de antelación, así como por incumplimiento grave de cualquiera de las partes de los acuerdos del convenio.

El Ministerio admite así que persisten sesgos discriminatorios de género en los procesos de selección de personal (también en la promoción profesional) para acceder a puestos de trabajo tanto en el ámbito público como en el privado, lo que provoca que se descarte con mayor frecuencia a "mujeres o a personas que tienen determinadas circunstancias familiares, edad, apariencia u otras" que pueden inducir a pensar que no son personas idóneas para determinados puestos. Para evitar estas prácticas se propone una medida innovadora, el CVA, que se define como "el que suprime referencias personales tales como el nombre y apellidos, sexo o edad, y no incluye tampoco fotografía, ni cualquier otro dato que pudiera dar lugar a cualquier sesgo discriminatorio en un proceso de selección de personal, con el fin de centrarlo en lo único que a priori tendría que ser relevante a la hora de acceder a un empleo o puesto, como serían la formación, cualificación, capacidades y perfil del candidato o candidata que mejor se adapta a la 
función a desarrollar" (cláusula segunda del modelo de Protocolo). Este CVA puede incorporarse progresivamente en función de las características de cada empresa o entidad y avanzar de este modo "de manera decidida en la consecución del objetivo de igualdad de trato y oportunidades, así como a una participación equilibrada de mujeres y hombres".

En 2018, ha aparecido también el CVA en el Plan Estratégico de Igualdad de Oportunidades 2018-2021. Dentro del Objetivo Específico 1.2. "Fomentar la igualdad de trato y oportunidades de mujeres y hombres en las empresas", encontramos la medida $\mathrm{n}^{\circ}$ 16: "[f]omentar la transparencia y eliminar sesgos discriminatorios en los procesos de selección en las empresas, a través de procedimientos objetivos y neutros (currículum ciego) y una mayor visibilización de las estadísticas de contratación y promoción profesional, desagregadas por sexo".

No nos consta que esta herramienta haya sido utilizada de forma habitual en España, pero tenemos algunos ejemplos anteriores a la iniciativa del Ministerio. Así, la empresa Renault Retail Group Barcelona, S.A., incluyó en 2016 la "Selección de personas con 'curriculum sin nombre' o 'ciego"' como acción a implantar dentro de su plan de igualdad $^{29}$. Ese mismo año, la empresa Unilever España, S.A. también lo empezó a usar $^{30}$. En las ofertas de empleo publicadas en su web se indica que el seleccionador elimina los datos personales del currículum de los candidatos y envía un CVA al director de contratación para evitar evaluaciones sesgadas ${ }^{31}$. Ambas empresas figuran en la lista de entidades adheridas al proyecto del Ministerio.

\section{La implantación de un sistema efectivo de CVA en la lucha contra la discriminación}

La implantación de un sistema efectivo de CVA necesita, en nuestra opinión, tres pilares básicos: uso de la tecnología informática, asesoramiento técnico-jurídico en el proceso y una política de empresa alineada con la lucha contra la discriminación.

\footnotetext{
${ }^{29}$ Convenio colectivo de trabajo de la empresa Renault Retail Group Barcelona, S.A. para los años 20162019 (Código de Convenio 08001592011994).

${ }^{30}$ Ficha de Unilever España, S.A. en la web de la Red de empresas con distintivo "Igualdad en la Empresa" (Red DIE) [en línea] [fecha de consulta 22/01/2019], disponible en: http://www.igualdadenlaempresa.es/redEmpresas/distintivo/docs/Unilever_ficha.pdf.

31 "At Unilever, we are firm believers in having a diverse and inclusive workplace. For that reason, we've committed to the blind CV. If you meet the requirements for the role, your recruiter will remove your personal details and send your blind $\mathrm{CV}$ to the hiring manager to ensure a non-biased evaluation based solely on your skills", Oferta HR Admin [en línea] [fecha de consulta 30/11/2018], disponible en: https://unilever.taleo.net/careersection/external/jobdetail.ftl?lang=en\&searchExpanded=true $\&$ job $=18000$ GNS.
} 


\subsection{Tecnología y CVA}

Puesto que estamos hablando de un currículum vitae donde no deben figurar datos personales como el nombre y apellidos, sexo, edad, etc. ni una fotografía del candidato, y que debe ser evaluado atendiendo a la información puramente académica y profesional, el proceso de recogida de esos datos debe ser realizado de forma anónima. Una primera opción consiste en que el propio candidato elimine los datos personales y la fotografía de su currículum y lo haga llegar así a las empresas que acepten este tipo de procedimiento. Una segunda opción implica que todo currículum vitae que llega a una empresa sea despojado de los datos personales por un seleccionador y enviado a otros seleccionadores para su evaluación ciega ${ }^{32}$. En nuestra opinión, si el objetivo de esta medida es evitar sesgos discriminatorios involuntarios del seleccionador, así como conductas discriminatorias conscientes, el proceso debe quedar libre de la intervención humana. Por lo tanto, para garantizar esa evaluación anónima y objetiva debe emplearse la tecnología informática desde el momento de la recepción de los datos del candidato.

Lo más adecuado parece recurrir a una plataforma web donde el candidato introduce sus datos personales y profesionales mediante un formulario o aplicación que permite anonimizar esa información. A continuación, un algoritmo informático con criterios establecidos analiza y cruza esos datos con los requisitos del puesto de trabajo ofrecido. Un algoritmo es un código software que procesa un conjunto limitado de instrucciones ${ }^{33}$ y que, según se diseñe, puede servir para evaluar el grado de adecuación de un candidato a una oferta. El resultado final es la continuación o el descarte del proceso de selección basado en datos objetivos y no discriminatorios. Dicho resultado se comunica al candidato mediante correo electrónico $\mathrm{y}$, si ha sido declarado apto, se le cita automáticamente a una entrevista final con los encargados de selección de personal donde se acabará perfeccionando el contrato de trabajo, si ambas partes consienten.

Con este sistema de CVA evitamos un foco importante de conductas discriminatorias que se producen en la fase de criba inicial de currículum vitae. Además, la propia

\footnotetext{
${ }^{32}$ Esta opción fue propuesta por las empresas de trabajo temporal adheridas al proyecto de CVA del Ministerio. Ellas convertirían el currículum vitae recibido en un CVA y lo enviarían así a sus empresas clientes. En este sentido, los headhunters, esto es, profesionales especializados en la selección de personal directivo y trabajadores de elevada cualificación, suelen presentar CVA a las empresas que recurren a ellos. Sin embargo, no lo hacen por una cuestión de prevención de la discriminación sino para preservar la identidad de los candidatos pues muchos de ellos se encuentran empleados.

${ }^{33}$ Monasterio AstobizA, A., "Ética algorítmica: implicaciones éticas de una sociedad cada vez más gobernada por algoritmos", Dilemata, 2017, n 24, p. 186.
} 
plataforma web puede incluir diversas pruebas de selección como test psicotécnicos, pruebas de conocimientos, de habilidad, etc. que mejoran el proceso y reducen los gastos asociados a este tipo de pruebas cuando se llevan a cabo de forma presencial. No obstante, reconocemos la dificultad que existe para diseñar un proceso de selección libre de toda intervención humana, especialmente si se desean cubrir determinados puestos de trabajo técnicamente complejos. Por ese motivo, parece ser que habrá una fase final, previa a la efectiva contratación, donde la identidad del candidato sea descubierta.

En este punto debemos señalar que determinados riesgos para los derechos fundamentales debido al uso de algoritmos informáticos, inteligencia artificial, macrodatos y tomas de decisiones automatizadas han sido advertidos recientemente ${ }^{34}$. Se sabe que los algoritmos reproducen comportamientos discriminatorios (origen racial, etnia, género $)^{35}$ e incluso pueden favorecer la discriminación indirecta por razón de sexo $^{36}$. De hecho, en ocasiones ni siquiera el propio creador del algoritmo es capaz de prever las consecuencias de su uso y su repercusión en los derechos fundamentales ${ }^{37}$,

Esto significa que el diseño de la plataforma, los formularios, el algoritmo, las pruebas, etc. debe llevarse a cabo con la máxima atención a la normativa y jurisprudencia que hemos mencionado en anteriores epígrafes, utilizándose baremos libres de sesgos discriminatorios $^{38}$. Una herramienta útil para evitar estos sesgos es la evaluación de impacto incorporada por el nuevo Reglamento (UE) 679/2016, del Parlamento Europeo y del Consejo, de 27 de abril de 2016, relativo a la protección de las personas físicas en lo que respecta al tratamiento de datos personales y a la libre circulación de estos datos y por el que se deroga la Directiva 95/46/CE (Reglamento general de protección de datos, en adelante RGPD). Dicha evaluación de impacto debe realizarse con carácter previo al tratamiento de datos, cuando sea probable que, por su naturaleza, alcance, contexto o fines, entrañe un alto riesgo para los derechos y libertades de las personas físicas. En este sentido, el uso de algoritmos informáticos que evalúan datos de candidatos (experiencia profesional, edad, sexo, localización geográfica, etc.)

\footnotetext{
${ }^{34}$ Véase la Resolución del Parlamento Europeo, de 14 de marzo de 2017, sobre las implicaciones de los macrodatos en los derechos fundamentales: privacidad, protección de datos, no discriminación, seguridad y aplicación de la ley.

${ }^{35}$ Ejemplos de discriminaciones por esos factores pueden verse en Monasterio AstobiZA, A., "Ética algorítmica: implicaciones...", op. cit., p. 198.

${ }^{36}$ BALLESTER PASTOR, M. A., "Uber saca un estudio que culpa a las mujeres de la brecha salarial", Blog Argumentos en Derecho Laboral [en línea] [fecha de consulta 30/11/2018], disponible en: https://adriantodoli.com/2018/02/27/uber-saca-un-estudio-que-culpa-a-las-mujeres-de-la-brecha-salarial/.

${ }^{37}$ Monasterio Astobiza, A., "Ética algorítmica: implicaciones...", op. cit., p. 186.

38 "The ethical design of algorithms requires coordination between technical and philosophical resources of the highest caliber", GoOdman, B., y FlaXman, S., "European Union regulations on algorithmic decision-making and a 'right to explanation'”, AI Magazine, vol. 38, n 3, 2017, p. 56.
} 
conformando perfiles de estos ${ }^{39}$ consideramos que exigiría la realización de una evaluación de impacto en los términos del artículo 35.3 a) $\mathrm{RGPD}^{40}$.

De hecho, el proceso para implantar el CVA en una organización debe estar presidido no solo por la normativa antidiscriminatoria sino también por la relativa a la protección de datos de carácter personal. Así, los artículos 25.1 y 25.2 RGDP consideran la necesidad de tener en cuenta la privacidad en todo el ciclo de vida de la tecnología, desde la fase de diseño hasta su fin, tanto de los sistemas de información, como de las arquitecturas y redes de comunicación, los procesos productivos y de negocio desde el momento en que se diseña e inicia la gestión y ciclo de vida del tratamiento de datos ${ }^{41}$. Son los principios de privacidad por defecto y en el diseño, medidas preventivas donde debe integrarse la protección frente a la discriminación ${ }^{42}$. Recuérdese también que el artículo 22.3 RGPD establece que, ante decisiones automatizadas basadas en tratamientos de datos personales, el responsable del tratamiento "adoptará las medidas adecuadas para salvaguardar los derechos y libertades y los intereses legítimos del interesado, como mínimo el derecho a obtener intervención humana por parte del responsable, a expresar su punto de vista y a impugnar la decisión", en nuestro caso, de descarte de un proceso de selección de personal.

La empresa IKEA Ibérica S.A., adherida al proyecto de CVA del Ministerio, ha implantado un sistema similar al que hemos descrito como prueba piloto en sus tiendas de muebles de Madrid, Sevilla y Sabadell (Barcelona) ${ }^{43}$. Esta primera experiencia finalizará en 2019 y se realizará una evaluación final de su funcionamiento.

El proceso utiliza una plataforma web desarrollada por una consultora de recursos humanos especializada en transformación digital, evaluación psicométrica, ingeniería de software y marketing digital ${ }^{44}$. El proceso se divide en varias fases:

\footnotetext{
${ }^{39}$ Por "elaboración de perfiles" se entiende "toda forma de tratamiento automatizado de datos personales consistente en utilizar datos personales para evaluar determinados aspectos personales de una persona física, en particular para analizar o predecir aspectos relativos al rendimiento profesional, situación económica, salud, preferencias personales, intereses, fiabilidad, comportamiento, ubicación o movimientos de dicha persona física" (artículo 4 RGPD).

${ }^{40}$ PReCiado DomèneCh, C. H., El derecho a la protección de datos en el contrato de trabajo. Adaptado al nuevo Reglamento 679/2016, de 27 de abril, Thomson Reuters Aranzadi, Cizur Menor (Navarra), 2017, p. 164.

${ }^{41}$ MerCader Uguina, J. R., El futuro del trabajo en la era de la digitalización y la robótica, Tirant lo Blanch, Valencia, 2017, p. 208.

${ }^{42}$ Cotino Hueso, L., "Big data e inteligencia artificial. Una aproximación a su tratamiento jurídico desde los derechos fundamentales", Dilemata, no 24, 2017, p. 139.

${ }^{43}$ Se circunscribe el proyecto a los mencionados centros de trabajo porque son los que tienen instalado un sistema de centralización de datos.

${ }^{44}$ https:/comienzatuaventuraenikea.thekeytalent.com/
} 
En primer lugar, el candidato se registra en dicha plataforma y aporta datos personales que se anonimizan ya que, según informa la web, "solo los utilizaremos para extraer estadísticas al final del proceso de selección" 45 y "en los procesos de selección ocultaremos toda información que pueda generar algún sesgo (...) no podremos saber tu nombre, apellidos, género, edad, estado civil, correo electrónico o cualquier otro dato personal o de contacto". El candidato puede también adjuntar un currículum vitae tradicional, aunque eliminando los datos personales y la fotografía.

En segundo lugar, el candidato responde a unas preguntas a través de un formulario sobre la experiencia profesional en sectores como hostelería, almacén, comercio y retail, preferencias de áreas (ventas, logística, etc.) ${ }^{46}$ y tiendas IKEA donde trabajar (Madrid, Sevilla, Sabadell), número de horas, turnos y días con disponibilidad para trabajar, y retribución económica deseada. Estas preguntas sirven para filtrar a los candidatos que continuarán el proceso. El formulario incluye alguna pregunta sobre vida privada del candidato (“QQué sueles hacer en tu tiempo libre?”) ${ }^{47}$ y sobre su "situación actual" (estudiante, desempleado, pluirempleado, otros).

En tercer lugar, con los candidatos que han superado la criba se lleva a cabo una evaluación a través de la propia web con la finalidad de que puedan "mostrar sus habilidades". Se somete al candidato a tres pruebas online rápidas ${ }^{48}$, de uso sencillo ("no hostiles"), que proporcionan información al seleccionador para dirigir la entrevista personal de la última fase. Aquí finalizaría la parte anónima del proceso donde el análisis de la empresa se centraría en las habilidades y competencias del candidato, evaluadas a través de dichas pruebas.

En cuarto y último lugar, se invita al candidato a "pasar un día en nuestras tiendas para que conozcas tu próximo lugar de trabajo y las personas con las que compartirás tu día a día". En la tienda se agrupa a los candidatos en grupos de entre ocho y doce personas y son entrevistados y evaluados por tres o cuatro seleccionadores. La decisión de contratación se toma ese mismo día, aunque la incorporación se retrasa una semana aproximadamente por temas burocráticos.

\footnotetext{
${ }^{45}$ Se trata de estadísticas que el Ministerio obliga a recoger para que las empresas se las envíen y así pueda evaluar los resultados del proyecto y compararlos por años.

${ }^{46} \mathrm{Si}$ bien se ha centrado el proyecto en la selección de personal de tienda, IKEA Ibérica S.A. estima que podría aplicarse a la selección de trabajadores de cualquier nivel jerárquico.

${ }^{47}$ Se formula esta pregunta para comprobar si el candidato posee valores alineados con la empresa y para incorporarlo a grupos formados por trabajadores con similares intereses.

${ }^{48}$ Prueba de razonamiento lógico deductivo; prueba de multitarea; prueba sobre competencias.
} 
En una nota de prensa donde se muestran los primeros resultados de este proyecto de CVA, IKEA Ibérica S.A. afirma que durante la primera semana de activación del proyecto cerca de 330 candidatos se registraron a través de la web " $y$ en las primeras entrevistas personales, realizadas en la tienda del Ensanche de Vallecas, se ha recogido una tasa de éxito del 83,3\%, pues de los 18 candidatos seleccionados para esta fase, 15 se han incorporado finalmente a la plantilla"49.

Por su parte, la multinacional Unilever, cuya filial española está adherida al proyecto del Ministerio y que ya tenía implantado el CVA, dispone de un programa para seleccionar a recién titulados (Unilever Future Leaders Programme) donde se les plantean pruebas y entrevistas en formato digital con la finalidad de evaluar a los candidatos eliminando sesgos inconscientes, si bien la última fase también consiste en una serie de pruebas en las instalaciones de la empresa ${ }^{50}$.

A nuestro juicio, ambas empresas han llevado a cabo de forma bastante óptima el proceso de implantación del CVA pues se utiliza la tecnología para anonimizar los datos personales y para evaluar a los candidatos a través de pruebas sin intervención humana. Aún así, debería usarse algún tipo de programa de autentificación para que pueda acreditarse que quien realiza las pruebas virtuales es quien efectivamente se ha inscrito en el proceso y no otra persona ${ }^{51}$. Por otro lado, en el caso de IKEA Ibérica S.A., observamos también algunas deficiencias en el formulario establecido que pueden viciar el proceso. Este ejemplo nos sirve para enlazar con el segundo requisito para implantar un sistema de CVA eficaz en la lucha contra la discriminación: el diseño técnicojurídico.

\subsection{Diseño técnico-jurídico del proceso}

\footnotetext{
${ }^{49}$ IKEA IBÉRICA S. A., "IKEA apuesta por el CV anónimo en sus procesos de selección para favorecer la igualdad", Nota de prensa de 28 de abril de 2018, [en línea] [fecha de consulta 05/12/2018], disponible en: https://www.ikeainfo.com/prensa/nota.php?id nota=718.

${ }^{50}$ Véase https://www.unilever.co.uk/careers/graduates/diversity-and-inclusion.html y MORENO ROMERO, E., "Bienvenida Vera, y bienvenida toda la AI al empleo", Blog Edulcoro el empleo 2.0, [en línea] [fecha de consulta 05/12/2018], disponible en: http://edulcoro.blogspot.com/2018/05/bienvenida-vera-ybienvenida-toda-la-ai.html.

${ }^{51}$ Un ejemplo del uso de este tipo de tecnología en la educación online puede verse en NOGUERA, I., Guerrero-Roldán, A. E, Huertas, H., RocA, R. y Baneres, D., "Enhancing the quality of online assessment with the support of an e-authentication system", 10th International Conference on Education and New Learning Technologies (EDULEARN'18), p. 1893-1903, 2018, disponible en: DOI:10.21125/edulearn.2018.0546.
} 
Además del aspecto tecnológico debemos estar al cumplimento de la normativa antidiscriminatoria que, como se ha visto anteriormente, resulta un tanto generalista, contiene excepciones no siempre clarificadas y ha sido matizada por la jurisprudencia en determinados aspectos. Estas características provocan ciertas dificultades a la hora de implantar un proceso de CVA.

Por ejemplo, a la hora de establecer unos requisitos para el puesto de trabajo ofertado se corre el peligro de caer en discriminaciones indirectas. El supuesto más extendido es el de solicitar una titulación académica o profesional (requisito "neutro") que pocas mujeres poseen sin que este requisito esté justificado para el puesto a ocupar" ${ }^{52}$ El último caso destacable es la existencia de discriminación indirecta por razón de sexo al exigirse una altura determinada para el acceso de las mujeres a la profesión de policía (STJUE de 18 de octubre de 2017, C-409/16, asunto Kalliri).

Respecto a la existencia de puestos de trabajo específicos destinados exclusivamente para mujeres u hombres, recuérdese que el artículo 5 LOI establece que "no constituirá discriminación en el acceso al empleo, incluida la formación necesaria, una diferencia de trato basada en una característica relacionada con el sexo cuando, debido a la naturaleza de las actividades profesionales concretas o al contexto en el que se lleven a cabo, dicha característica constituya un requisito profesional esencial y determinante, siempre y cuando el objetivo sea legítimo y el requisito proporcionado". En ese sentido, la jurisprudencia comunitaria ha considerado que no se ajusta a derecho la exclusión total de las mujeres para el acceso a empleos militares que impliquen el uso de armas (STJUE de 11 de enero de 2000, C-285/98, asunto Kreil), trabajo en minas (STJUE de 1 de febrero de 2005, C-203/03, asunto Comisión contra Austria), tareas de buceo o en medios hiperbáricos (STJUE de 1 de febrero de 2005, C-203/03, asunto Comisión contra Austria) y trabajo nocturno (STJUE de 12 de julio de 1984, C-184/83, asunto Hoffmann, y de 25 de julio de 1991, C-345/89, asunto Stoecktel, entre otras).

Parece ser que los empleos relacionados con el mundo artístico, como modelos de ropa, de pintura, actores o figurantes de cine o teatro, etc., junto con ciertas actividades en hospitales, centros penitenciarios, o similares, en las que haya que preservar la intimidad personal, serán los que más fácilmente puedan justificar una diferencia de trato por razón de sexo, amparándose en la propia naturaleza de la actividad profesional $\operatorname{concreta}^{53}$. No cabe apelar a la costumbre, la tradición o cualquier otro motivo "social"

\footnotetext{
${ }^{52}$ Véanse los casos de la STS de 4 de mayo de 2000 (rec. no 3708/1999) y la STSJ de Cantabria de 14 de noviembre de 2005 (rec. $n^{\circ}$ 905/2005).

${ }^{53}$ Charro BAEna, P. Y SAN MARTín MAZZuCCONI, C., "Decálogo jurisprudencial básico sobre igualdad y no discriminación en la relación laboral", Revista del Ministerio de Trabajo y Asuntos Sociales, $\mathrm{n}^{\circ}$ Extra: Igualdad de oportunidades para todos, 2007, p. 88.
} 
para justificar la licitud de una oferta de empleo destinada únicamente a un sexo, pues precisamente han sido los motivos sociales o culturales los que han causado y causan la discriminación hacia el género femenino ${ }^{54}$. Tampoco cabe apelar a la específica situación de embarazo y su necesidad de protección pues la STJUE de 3 de febrero de 2000, C-207/98, asunto Mahlburg, ha indicado que "la aplicación de las disposiciones relativas a la protección de la mujer embarazada no puede tener por consecuencia un trato desfavorable en lo que atañe al acceso al empleo de una mujer embarazada",55.

En cuanto a establecer una edad mínima o máxima para el puesto de trabajo, las justificaciones a la diferencia de trato estipuladas en la Directiva son amplias, pero debe estarse al sector o puesto de trabajo concreto. En cualquier caso, si la empresa desea acogerse a los diversos incentivos económicos a la contratación (jóvenes, mayores de 45 años, etc.) debe contemplarse esta posibilidad a la hora de diseñar el algoritmo informático, por ejemplo, otorgando prioridad o preferencia por los candidatos que cumplan con estas características. Lo que no resulta tolerable es exigir un rango de edad no contemplado para dichos incentivos, por ejemplo, "edad entre 35 y 45 años" (STSJ de Cataluña de 10 de noviembre de 2006, rec. nº 276/2002).

La misma modificación de los criterios del algoritmo deberá efectuarse, por ejemplo, para adaptar las posibles medidas de acción positiva acordadas mediante negociación colectiva o la cuota de reserva de puestos para personas con discapacidad.

Volviendo al caso de IKEA Ibérica S.A., deben mejorarse dos aspectos del formulario:

En primer lugar, las preguntas relativas a las aficiones del candidato deben ser eliminadas. Según una construcción doctrinal, el derecho a la intimidad del candidato (artículo 18.1 CE) puede ser lesionado durante el transcurso de un proceso de selección si se intenta obtener información sobre aspectos no relacionados directamente con la aptitud profesional requerida por el puesto de trabajo a desempeñar ${ }^{56}$.

En segundo lugar, las preguntas sobre jornada y turnos de trabajo pueden provocar discriminaciones indirectas por razón de sexo si el algoritmo que evalúa a los

\footnotetext{
${ }^{54}$ Fabregat Monfort, G., La discriminación de género en el acceso al mercado de trabajo, Tirant lo Blanch, Valencia, 2008, p. 92. En ese sentido, se produce discriminación por razón de sexo cuando se desestima la contratación de una desempleada enviada por un servicio público de empleo autonómico a una empresa ya que esta, a su criterio, "consideraba que era más apropiado para el puesto de trabajo, un hombre" (STSJ de Andalucía, Granada, de 22 de febrero de 2012, rec. no 2880/2011). En relación a estereotipos de género y reparto tradicional de roles, véase también la STEDH de 22 de marzo de 2012, asunto Konstantin Markin contra Rusia.

55 En el mismo sentido, STC 229/1992, de 14 de diciembre, entre otras.

${ }^{56}$ GoÑI SEIN, J.L., El respeto a la esfera privada del trabajador, Civitas, Madrid, 1988, p. 49.
} 
candidatos se diseña sin atender a criterios antidiscriminatorios. Se sabe que algunas disposiciones normativas relacionadas con el trabajo a tiempo parcial han sido fuente de discriminaciones indirectas hacia el colectivo femenino ${ }^{57}$. También las preguntas sobre la situación de desempleo del candidato debieran evitarse pues, además de no estar relacionadas con el puesto a cubrir, se ha demostrado que los candidatos que llevan más tiempo desempleados tienen más posibilidades de ser descartados ${ }^{58}$.

\subsection{Política de empresa alineada con la igualdad}

En determinados sectores o empresas, pese a que las mujeres no se les impide abiertamente participar en un proceso de selección, la decisión de descartarlas está tomada desde el primer momento. Valga el ejemplo transcrito por PONTÓN MERINO Y PASTOR GOSÁlBEZ en una de sus obras: "yo he oído cómo el director de recursos humanos le decía a la hija de un compañero que venía a una entrevista para operario, que no hacía falta que perdiera el tiempo en el proceso, que la empresa no quería mujeres operarias, que la llamaban porque todos tenían derecho a optar al puesto, pero que no la iban a coger" 59 . Con este ejemplo pretendemos ilustrar que, aún disponiendo de tecnología y asesoramiento técnico-jurídico, si la empresa no tiene instaurada una política alineada con la igualdad en el trabajo, el CVA no podrá ser implantado de forma eficaz.

En ese sentido, un estudio de la consultora Hays indica que un 63\% de las empresas encuestadas no desea incorporar el CVA en sus procesos de selección ${ }^{60}$. No parece el caso de las 92 entidades adheridas al proyecto del Ministerio, entre las que se encuentran algunas de las poseedoras del distintivo "Igualdad en la Empresa"61. Aún así, nos resulta extraño observar en dicha lista a tres empresas de trabajo temporal (que también realizan actividades de selección de personal) y un portal virtual de empleo. Nos tememos que no tengan esa voluntad de implantar un sistema de CVA ni para su uso interno ("seleccionar al seleccionador") ni para ofrecérselo a sus empresas clientes. Hace años que nuestra doctrina ha afirmado que los empresarios tienen interés en acudir

\footnotetext{
${ }^{57}$ Véase la STJUE de 9 de noviembre de 2017, C-98-15, asunto Espadas Recio, relativa a la prestación por desempleo derivada del trabajo a tiempo parcial.

${ }^{58}$ GHAYAd, R. y Dickens, W. T., "What Can We...", op. cit.

${ }^{59}$ PONTÓN MERINO, P. y PASTOR GosÁlBez, I, "Los convenios colectivos como herramienta para alcanzar la igualdad de género en el trabajo. Estudio de caso: la industria química en Tarragona", BARATARIA Revista Castellano-Manchega de Ciencias Sociales, 2014, $\mathrm{n}^{\circ}$ 18, p. 124, disponible en: DOI: http://dx.doi.org/10.20932/barataria.v0i18.47.

${ }^{60}$ HAYS, Guía del mercado laboral 2018, [en línea] [fecha de consulta 21/01/2019], disponible en: http://guiasalarial.hays.es/trabajador/encuestas/empresas\#pregunta81.

${ }^{61}$ Véase el artículo 50 LOI y el Real Decreto 1615/2009, de 26 de octubre, por el que se regula la concesión y utilización del distintivo "Igualdad en la Empresa".
} 
a las empresas de selección porque consienten con mayor facilidad la imposición de condiciones de acceso al empleo discriminatorias, ajenas a las condiciones objetivas del puesto de trabajo a cubrir ${ }^{62}$. Por su parte, se ha detectado que los portales de empleo ${ }^{63} \mathrm{y}$ las aplicaciones móviles para buscar trabajo ${ }^{64}$ se han convertido en un terreno abonado a la vulneración del principio de igualdad y no discriminación, publicando ofertas abiertamente discriminatorias por razón de $\operatorname{sexo}^{65}$ y por razón de edad ${ }^{66}$. Nos encontramos ante intermediarios fuera de control a los que los poderes públicos han acabado imponiendo únicamente una declaración responsable de actividad (artículo 33.2 LE) en lugar de reforzar el régimen de autorización administrativa que regía (aunque con poco éxito) hasta la reforma de la LE en 2015.

El sincero interés por la implantación del CVA se desprende de acciones como las de la empresa IKEA Ibérica S.A. que es la que más difusión ha hecho de esta medida a través de notas de prensa y ofreciendo datos sobre los resultados que va obteniendo. No nos consta que ninguna otra lo haya hecho. Además, ha incluido el CVA en su II Plan de Igualdad $^{67}$. Recuérdese que los planes de igualdad consisten en "un conjunto ordenado de medidas, adoptadas después de realizar un diagnóstico de situación, tendentes a alcanzar en la empresa la igualdad de trato y de oportunidades entre mujeres y hombres y a eliminar la discriminación por razón de sexo" (artículo 46.1 LOI). Los planes de igualdad son de obligada elaboración en cuatro supuestos (artículo 45 LOI): para las empresas de más de 250 trabajadores $^{68}$; para las empresas cuyo convenio colectivo aplicable así lo establezca; para las empresas que voluntariamente así lo deseen, previa consulta con los representantes de los trabajadores; y, finalmente, cuando la autoridad laboral hubiera acordado en un procedimiento sancionador la sustitución de las

\footnotetext{
${ }^{62}$ GoÑI SeIN, J.L., El respeto a la esfera privada..., op. cit., p. 80-81 y DE Vicente PACHÉS, F., El derecho del trabajador al respeto de su intimidad, Consejo Económico y Social, Madrid, 1998, p. 131.

${ }^{63}$ El único portal de empleo adherido a esta iniciativa de CVA (Infojobs) dispone de una opción para que un usuario-empresa pueda descartar indefinidamente al usuario-candidato que desee, por lo que no podrá optar a presentarse a las ofertas de empleo publicadas por la empresa en cuestión.

${ }^{64}$ FERNÁNDEZ GARCíA, A., "Aplicaciones móviles para buscar empleo: aspectos jurídico-laborales” en Todolí Signes, A. y Hernández Bejarano, M. (Coordinadores.), Trabajo en Plataformas Digitales: innovación, Derecho y mercado, Thomson Reuters Aranzadi, Cizur Menor (Navarra), 2018, p. 476.

${ }^{65}$ Chacartegui Jávega, C., "Incidencia de nuevas TIC...”, op. cit., p. 12.

${ }^{66}$ INFOEMPLEO-ADECCO, Informe Infoempleo Adecco 2017, [en línea] [fecha de consulta 21/01/2019], p. 142, disponible en: https://www.infoempleo.com/informe-infoempleo-adecco/.

${ }^{67}$ II Plan de Igualdad IKEA Ibérica S.A., [en línea] [fecha de consulta 22/01/2019], disponible en: http://www.igualdadenlaempresa.es/redEmpresas/distintivo/docs/IKEA Plandeigualdad.pdf.

${ }^{68}$ En muchas ocasiones, se aprecia que el compromiso que asumen los convenios de sector no es general, sino que sólo se intenta rebajar ligeramente la obligación legal (por ejemplo, para que afecte no a las empresas de más de 250 trabajadores, sino simplemente a las de más de 100 o más de 150, LuJáN Alcaraz, J. y Selma Penalva, A., "Planes de igualdad", en Sánchez Trigueros, C. (Directora), Kahale Carrillo, D. T. y Velasco Portero, T. (Coordinadores), El principio de igualdad en la negociación colectiva, Ministerio de Empleo y Seguridad Social, Madrid, 2016, p. 487.
} 
sanciones accesorias por la elaboración y aplicación de dicho plan, en los términos que se fijen en el indicado acuerdo.

Estos planes de igualdad pueden referirse a diversas materias, entre ellas, el acceso al empleo (artículo 46.2 LOI) y se ha afirmado que esta debería ser siempre una cuestión a abordar en todo plan de igualdad que realmente quiera ser efectivo ${ }^{69}$. Las medidas relacionadas con el acceso al empleo pueden ser muy diversas dependiendo del diagnóstico de la situación realizado previamente y de los objetivos que se fijen ${ }^{70}$, y no cabe duda de que un sistema de CVA encaja en esa categoría pues "la eliminación de la desigualdad entre mujeres y hombres en este primer estadio de la relación laboral, debe pasar obligatoriamente por seleccionar a la mejor persona para cada puesto de trabajo, independientemente de cuales sean sus características naturales, culturales, sociales y personales, mediante la realización de procesos de selección no discriminatorios, tanto en su configuración como en su aplicación" ${ }^{\text {"71 }}$.

Así lo ha hecho IKEA Ibérica S.A., puesto que su II Plan de Igualdad contiene el objetivo de "[g]arantizar la igualdad de oportunidades revisando nuestros procesos de selección" y la primera de las medidas a adoptar la constituye "[u]tilizar un CV ciego en los procesos de selección de personal". El responsable de esa medida será el Responsable de Selección de la empresa y tendrá un plazo de vigencia idéntico al del plan de igualdad. Otras medidas acordadas en relación con esta materia son el uso de lenguaje e imágenes no sexistas en las ofertas de empleo; formar a los seleccionadores de personal en materia de igualdad de oportunidades; informar de los criterios de selección por valores y la política de igualdad a las empresas de selección con las que se trabaje; garantizar la objetividad del sistema de selección establecido, etc. Nótese que la mayoría de medidas permiten luchar contra cualquier tipo de discriminación y no solo contra la discriminación por razón de sexo.

Otros objetivos de este II Plan de Igualdad se centran en fomentar una representación equilibrada de hombres y mujeres en los distintos grupos profesionales, especialmente

\footnotetext{
${ }^{69}$ FABREgat MONForT, G., "La incidencia de la Ley Orgánica 3/2007, de 22 de marzo, para la igualdad efectiva de mujeres y hombres en materia de negociación colectiva. En especial, en los planes de igualdad", en Romero Burillo, A. M. y RodríGuez Ordaz, C. (Coordinadoras), Trabajo, género e igualdad, Thomson Reuters Aranzadi, Cizur Menor (Navarra), 2018, p. 384-385.

${ }^{70}$ Todo plan de igualdad exige un proceso previo de elaboración individualizada destinado a garantizar la razonabilidad de las medidas acordadas y su utilidad para solventar los problemas detectados, LUJÁN AlCARAZ, J. y Selma PenAlVA, A., "Planes de igualdad", op. cit., p. 487.

${ }^{71}$ Rodríguez CRespo, M. J., "Políticas activas de empleo para mejorar la inserción laboral de las mujeres: políticas públicas en retroceso y derechos indisponibles en tiempos de crisis", en SÁEz LARA, C. (Coordinadora), Igualdad de género en el trabajo: estrategias y propuestas, Ediciones Laborum, Murcia, 2016, p. 34.
} 
en los subrepresentados. Para ello, una medida propuesta es la de obtener datos referidos a los procesos de selección en cuanto a género en los centros de nueva apertura, lo que tiene relación con los datos estadísticos que pueden obtenerse a través del sistema informático del CVA. De hecho, se aplica esta información a otras medidas del plan de igualdad. Finalmente, el plan incorpora medidas de acción positiva similares a las mencionadas en el ET.

En cualquier caso, aunque en una empresa no exista obligación expresa de elaborar un plan de igualdad puede instaurarse un sistema de CVA ya que el artículo 45 LOI exige la implantación de medidas aisladas para garantizar la igualdad entre hombres y mujeres, previa negociación con los representantes de los trabajadores. Piénsese que el precepto exige de forma tácita un diagnóstico previo de la situación y un sistema de control mínimo de que se cumplen estas medidas aisladas: incremento de competencias de la comisión paritaria, intervención de los representantes de los trabajadores, creación de agentes o comisiones de igualdad, etc. ${ }^{72}$.

Finalmente, para fomentar el CVA u otro tipo de medidas antidiscriminatorias puede resultar útil promover y publicitar incentivos como los contenidos en el artículo 147.1 de la Ley 9/2017, de 8 de noviembre, de Contratos del Sector Público, por la que se transponen al ordenamiento jurídico español las Directivas del Parlamento Europeo y del Consejo 2014/23/UE y 2014/24/UE, de 26 de febrero de 2014. Este precepto permite establecer criterios de adjudicación específicos para dirimir un empate entre dos o más ofertas que consisten, entre otros, en el porcentaje de personas con discapacidad en plantilla o en la existencia de medidas para garantizar la igualdad entre hombres y mujeres.

Disponer de un sistema de CVA también puede ayudar a conseguir distintivos como el mencionado "Igualdad en la Empresa" o certificaciones como el sello Bequal, que distingue a las compañías como socialmente responsables con la discapacidad ${ }^{73}$. Siguiendo en materia de responsabilidad social corporativa, se ha afirmado que la Unión Europea "está concienciada de que las empresas deben integrar la gestión de la

\footnotetext{
${ }^{72}$ FABRegat Monfort, G., "La incidencia de la Ley Orgánica...”, op.cit., p. 390.

73 "El mínimo nivel exigido para distinguir a las compañías como socialmente responsables con la discapacidad requiere un compromiso al menos en tres áreas esenciales, la Estrategia y Liderazgo, es necesario el compromiso de la alta dirección hacia las personas con discapacidad, la Gestión de los Recursos Humanos, no solo con el cumplimiento de la normativa, sino también aplicando políticas de no discriminación e igualdad de oportunidades en todos los procedimientos de selección, acceso al empleo, promoción profesional y formación, y por último, en las empresas, se debe contemplar la Accesibilidad universal tanto a las instalaciones, como la comunicación interna y con los proveedores y en la prevención de riesgos laborales", [en línea] [fecha de consulta 22/01/2019], disponible en: http://www.bequal.es/servicios/sello-bequal.
} 
diversidad (incluyendo la de género) en su estrategia de negocio y de gobernanza, por los beneficios que se generan tanto socialmente como para la propia organización, y que las entidades deben informar adecuadamente sobre ello"74. De ahí que, no solo la política de empresa alineada con la igualdad sea clave para implantar el CVA, sino que también resulta conveniente publicitar este tipo de medidas exista o no una obligación legal para ello.

\section{La prueba de la discriminación y el CVA}

Una crítica al uso del CVA es que únicamente sirve para evitar la discriminación en la primera fase de un proceso de selección ${ }^{75}$. Así, al llegar a la fase de entrevista personal el seleccionador obtendría información que le permitiría tomar una decisión discriminatoria. En nuestra opinión, cuanto más avanza un candidato en un proceso de selección más posibilidades tiene de demostrarse la discriminación.

Piénsese que, en un proceso no anónimo, si se desea discriminar a determinados colectivos (mujeres, por ejemplo), pueden descartarse esos currículums vitae en el momento en que se reciben en la empresa, quedando tal discriminación totalmente oculta. En cambio, si el candidato "no deseado por la empresa" es discriminado durante la fase de entrevista, las posibilidades de probar dicha conducta son más elevadas, lo que puede dar lugar a la interposición de una demanda judicial con garantías y la obtención de una indemnización por daños y perjuicios, así como a la intervención de la Inspección de Trabajo y Seguridad Social.

Este último supuesto se produce en la STSJ de Canarias, Santa Cruz de Tenerife, de 7 de abril de $2014^{76}$ : en el transcurso de una entrevista de trabajo los seleccionadores formularon preguntas a una candidata relacionadas con su situación personal (marido, hijos) y le comentaron las dificultades que tendría para encontrar colegio para sus hijas y para que su marido consiguiera trabajo en la zona además de advertirle que "no querían a alguien que se cogiera una baja por maternidad". La propia aspirante informó en ese momento que se había ligado las trompas y que no podía tener más hijos; sin embargo, fue descartada del proceso de selección mientras que otra candidata fue contratada tras indicar en la entrevista que no tenía pareja ni hijos. El juzgador es contundente en sus argumentos ${ }^{77} \mathrm{y}$ declara que la indemnización que corresponde

\footnotetext{
${ }^{74}$ SAITUA IRIBAR, A., "Diversidad de género como parte de la RSC y sostenibilidad en las empresas. Avances para la mejora de la divulgación de información no financiera sobre las políticas de igualdad y sus resultados", Lan Harremanak: Revista de relaciones laborales, 2017, nº 38, p. 198.

${ }^{75}$ RINNE, U., “Anonymous job applications and hiring discrimination”, IZA World of Labor, 2018, n 48, Disponible en: doi: 10.15185/izawol.48.v2.

${ }^{76}$ Rec. no 923/2012.

77 "El hecho de someter a una candidata a preguntas familiares y personales totalmente ajenas al trabajo
} 
abonar a la candidata por daños y perjuicios asciende a 3.000 euros.

Otro ejemplo en el que se demuestra una discriminación en fases avanzadas de un proceso de selección es el contenido en la STSJ de Murcia, de 5 de julio de 2011 (rec. n $^{\circ}$ 59/2011): quedando pendiente únicamente concretar las condiciones económicas, la firma del contrato y el alta en la Seguridad Social, la empresa elude proseguir con dichas actuaciones al comunicarle la candidata su estado de embarazo. Previamente, existió voluntad de contratar a dicha candidata tras alcanzar un acuerdo con ella a través de dos correos electrónicos e incluso recibió información en la misma empresa relacionada con las tareas a desempeñar y los programas informáticos a utilizar.

A esta posibilidad probatoria que aumenta según se avanza en el proceso de selección hay que sumarle lo dispuesto en la LRJS. Por un lado, su artículo 96.1 establece que "en aquellos procesos en que de las alegaciones de la parte actora se deduzca la existencia de indicios fundados de discriminación por razón de sexo, orientación o identidad sexual, origen racial o étnico, religión o convicciones, discapacidad, edad, acoso y en cualquier otro supuesto de vulneración de un derecho fundamental o libertad pública, corresponderá al demandado la aportación de una justificación objetiva y razonable, suficientemente probada, de las medidas adoptadas y de su proporcionalidad". Por otro lado, el artículo 182.2 indica que "en el acto del juicio, una vez justificada la concurrencia de indicios de que se ha producido violación del derecho fundamental o libertad pública, corresponderá al demandado la aportación de una justificación objetiva y razonable, suficientemente probada, de las medidas adoptadas y de su proporcionalidad".

De este modo, especialmente en casos de discriminación directa y en orden a evitar "que la imposibilidad de revelar los verdaderos motivos del acto empresarial impida declarar que este resulta lesivo del derecho fundamental" (STC 38/1981, de 23 de noviembre y 87/2004, de 10 de mayo), se articula la distribución de la carga de la prueba mediante dos fases diferenciadas:

En un primer momento, la parte demandante, en nuestro caso el candidato al puesto de trabajo que ha superado la fase anónima del proceso debe aportar un indicio razonable de prueba de que el seleccionador o empresario ha vulnerado su derecho fundamental a

a desempeñar, sea cual sea el lugar de prestación de los servicios (pues ya había manifestado su disponibilidad a desplazarse), supone una conducta discriminatoria, puesto que la trabajadora se ha visto obligada revelar sus planes familiares y datos médicos pertenecientes a su más estricta intimidad, innecesarios para una gestión de personal responsable y respetuosa con la dignidad del empleado (...) la discriminación hacia la mujer se produce hacia ésta por un factor añadido inherente a su sexo, el ser 'madre', y la situación de maternidad'. 
no ser discriminado durante la fase de entrevista. Este indicio fundado "no consiste en la mera alegación de la vulneración constitucional, sino que debe permitir deducir la posibilidad de que aquélla se haya producido" (STC 87/2004, de 10 de mayo), "ha de acreditar la existencia de indicios que generen una razonable sospecha, apariencia o presunción en favor de semejante alegato" (STC 136/1996, de 23 de julio).

Algunos ejemplos de esta situación se darían si, de un grupo de candidatos que superan la fase de criba anónima de currículum vitae, tras la entrevista personal solo fueran descartados los pertenecientes a un determinado sexo, o a una determinada raza o etnia, o las personas con discapacidad, etc. También serviría de indicio el hecho de formular preguntas relacionadas con el estado de embarazo, o el estado civil, o las responsabilidades familiares, o sobre afiliación sindical, etc. Recuérdese que la entrevista puede ser registrada mediante un sistema de grabación sonora que porte oculto el candidato, por ejemplo, un teléfono móvil. Dicha grabación puede aportarse en un proceso judicial en virtud del artículo 90.1 LRJS pues, según la doctrina, no se conculcan ni el derecho a la intimidad ni el secreto de las comunicaciones siempre que la grabación la realice uno de los interlocutores (STC 114/1984, de 29 de noviembre).

Una vez aportado el indicio, "sobre la parte demandada recae la carga de probar que su actuación tiene causas reales absolutamente extrañas a la pretendida vulneración de derechos fundamentales, así como que aquellas tuvieron entidad suficiente como para adoptar la decisión, único medio de destruir la apariencia lesiva creada por los indicios" (SSTC 38/1981, de 23 de noviembre y 87/2004, de 10 de mayo, entre otras). De ahí que los preceptos legales hablen de "la aportación de una justificación objetiva y razonable, suficientemente probada, de las medidas adoptadas y de su proporcionalidad" (artículos 96.1 y 181.2 LRJS), y nuestra doctrina asevere a su vez que "se trata, en definitiva, de que el empleador acredite que tales causas explican objetiva, razonable y proporcionadamente por sí mismas su decisión, eliminando toda sospecha de que aquella ocultó la lesión de un derecho fundamental del trabajador" (SSTC 38/ 1981, de 23 de noviembre y 87/2004, de 10 de mayo, entre otras).

Hay que aclarar que no se impone al empresario "la prueba diabólica de un hecho negativo -la no discriminación-, sino la de la razonabilidad y proporcionalidad de la medida adoptada y su carácter enteramente ajeno a todo propósito atentatorio de derechos fundamentales" (STC 136/1996, de 23 de julio). No basta, pues, "el mero intento de negar la vulneración de derechos fundamentales" (STC 87/2004, de 10 de mayo).

El empresario debería ofrecer una justificación razonable de que el descarte ha sido llevado a cabo con respeto a los derechos fundamentales, sin discriminación por los 
factores tasados en la normativa o bien por haberse acogido a alguna de las excepciones a la igualdad de trato que hemos expuesto en anteriores epígrafes.

En caso de que el empresario no aporte la justificación objetiva, razonable y suficientemente probada, se "determina, en último término, que los indicios aportados por el demandante despliegan toda su operatividad para declarar la lesión del propio derecho fundamental del trabajador" (STC 136/1996, de 23 de julio y 87/2004, de 10 de mayo, entre otras).

Si la sentencia estima que se ha vulnerado el derecho fundamental a la no discriminación durante un proceso de selección de personal, declarará la nulidad radical de la conducta lesiva (la discriminación del candidato) y la reposición de la situación al momento anterior a producirse la lesión del derecho fundamental. Además, se repararán las consecuencias derivadas de la acción u omisión del sujeto responsable, incluyendo la indemnización que proceda (artículo 182.1 LRJS). La reposición a la que se refiere el precepto puede suponer la obligación de contratar al candidato (STSJ Islas Canarias, Las Palmas, de 22 de diciembre de 2008, rec. $n^{\circ}$ 980/2007) aunque la STJUE de 10 de abril de 1984, C-14/83, asunto Von Colson y Kamann, ha aclarado que la normativa no obliga a dicha contratación, pero sí a que las indemnizaciones sean efectivas, proporcionadas y disuasorias. Parece que lo más extendido es indemnizar al candidato discriminado siempre que conste "la existencia de daños y perjuicios y la prueba de los mismos" $"$.

La cuantía de la indemnización suele calcularse de forma similar a los supuestos de incumplimiento de un precontrato de trabajo, esto es, atendiendo a los salarios dejados de percibir desde la fecha en que el candidato hubiera ingresado en la empresa ${ }^{79}$ y puede incluir los daños morales si estos se prueban, por ejemplo, los 6.000 euros dictaminados en la STSJ Islas Canarias, Las Palmas, de 22 de diciembre de 2008 (rec. nº 980/2007) o los 30.000 euros (sumando daño patrimonial y moral sin distinción entre ellos) de la STS de 12 de noviembre de 2015 (rec. nº 899/2014).

A pesar de esta tutela procesal, la realidad es que las demandas relativas a estos estadios previos de la relación laboral son muy escasas ${ }^{80}$. Esto podría cambiar con la

\footnotetext{
${ }^{78}$ STS de 26 de octubre de 2005, rec. no 1388/1999, de 12 de diciembre de 2007, rec. n 25/2007 y de 22 de octubre de 2009 , rec. $n^{\circ} 3742$, entre otras.

${ }^{79}$ STS de 22 de octubre de 2009, rec. no 3742/2008, STS de 15 de septiembre de 2009, rec. no 3258/2008, STSJ Islas Canarias, Las Palmas, de 22 de diciembre de 2008, rec. no 980/2007 y STSJ de Cantabria de 20 de febrero de 2008, rec. $n^{\circ}$ 60/2008.

${ }^{80}$ ChacARtegui Jávega, C., “Incidencia de nuevas TIC...”, op. cit., p. 19.
} 
popularización del CVA pues ya hemos comprobado cómo facilita la prueba de la discriminación en los procesos de selección de personal.

\section{Conclusiones}

En España disponemos de normativa que proscribe de forma general la discriminación en el acceso al empleo y que deja la regulación específica en manos de la negociación colectiva. La vía administrativa de tutela se centra en sancionar las conductas empresariales discriminatorias incluyendo la publicación y difusión de ofertas de empleo con esas características. Se prevé también una modalidad procesal específica a la que puede acudir el candidato que considere vulnerado su derecho a no ser discriminado durante un proceso de selección de personal. Se conforman así dos grupos de medidas: unas de tipo preventivo y otras reparadoras del daño causado.

El CVA constituye una medida eficaz para luchar contra la discriminación en el acceso al empleo y posee características tanto preventivas como reparadoras. Respecto a la prevención, parece que elimina los sesgos involuntarios del seleccionador al establecer un sistema objetivo de evaluación de candidatos. Respecto a la reparación del daño, facilita la capacidad de probar durante un proceso judicial las decisiones y órdenes discriminatorias del empresario que se produzcan durante las fases no anónimas del proceso de selección (entrevista, por ejemplo).

No obstante, para la implantación de un sistema efectivo de CVA se necesitan, en nuestra opinión, tres pilares básicos: uso de la tecnología informática, asesoramiento técnico-jurídico en el proceso y una política de empresa alineada con la lucha contra la discriminación. Respecto a esto último, entendemos que el CVA debe incorporarse a todo plan de igualdad que lo requiera, aunque nada impide que se implante como medida aislada mediante acuerdo entre la empresa y los representantes de los trabajadores.

Además, esta medida puede incluirse en el ámbito de la responsabilidad social corporativa, permite colaborar en la obtención de certificaciones y sellos distintivos y ayudar en la adjudicación de contratos en el sector público.

Los inconvenientes más destacables del CVA serían la complejidad y coste elevado de su implantación ya que, como hemos señalado, resulta imprescindible el recurso a herramientas tecnológicas avanzadas y a un importante asesoramiento técnico- 
jurídico $^{81}$. El uso de tecnología dificulta a su vez que las personas con poca formación digital se presenten a procesos de selección que empleen el CVA. Paradójicamente, esos grupos de "analfabetos digitales" suelen formar parte de los grupos con mayor posibilidad de ser discriminados o excluidos del mercado laboral (mayores, amas de casa, parados, etc. $)^{82}$.

No cabe duda de que el proyecto de CVA impulsado desde el Ministerio hace más de un año ha abierto el debate sobre esta herramienta y sobre la necesidad de evitar sesgos inconscientes durante la selección de personal, momento precontractual donde se producen conductas ilícitas y situaciones de desventaja para determinados colectivos difíciles de denunciar y erradicar. A nuestro entender, cada vez aparecen más factores que merecen una atención por parte de la normativa antidiscriminación. Así, el sobrepeso y la obesidad han obtenido la tutela antidiscriminatoria por vía del artículo 37 de la Ley 17/2011, de 5 de julio, de seguridad alimentaria y nutrición (se prohíbe la discriminación directa e indirecta por ambas razones). Si bien su aplicación al ámbito laboral y prelaboral no ha quedado del todo clara, puede abrirse el camino para incorporar, por vía legal o convencional, otras causas habituales que "en la práctica quedan en el desamparo, como sucede con el aspecto físico en términos generales" con la enfermedad ${ }^{84}$.

\section{Bibliografía}

Alameda Castillo, M. T., Estadios previos al contrato de trabajo y discriminación, Thomson Reuters Aranzadi, Cizur Menor (Navarra), 2014.

Alter, Los perfiles de la discriminación en España: Análisis de la Encuesta CIS-3.000 Percepción de la discriminación en España, Ministerio de Sanidad, Servicios Sociales e Igualdad, Madrid, 2014.

\footnotetext{
${ }^{81}$ En este sentido, el proyecto de CVA impulsado por el Ministerio no prevé financiación alguna para las entidades adheridas y el asesoramiento técnico mencionado en el modelo de protocolo no nos consta que se esté llevando a cabo.

${ }^{82}$ Fernández EngutTa, M., "El futuro digital y la desigualdad que viene", en Ayala CAÑón, L. Y RuizHuerta CARbonell, J. (Directores), 3er Informe sobre la desigualdad en España, Fundación Alternativas, Madrid, 2018, p. 276.

${ }^{83}$ RIVAS VALLEJO, P., “¿Es la obesidad causa de discriminación tutelable en el ámbito laboral?”, IUSLabor, $\quad \mathrm{n}^{\circ} \quad 1 / 2015, \quad$ p. $\quad 29, \quad$ disponible https://www.raco.cat/index.php/IUSLabor/article/view/288502.

${ }^{84}$ Véase Beltran DE HeRedia RUIZ, I., "Extinción del contrato durante enfermedad o dolencia de larga duración: Doctrinas Chacón Navas, Danmark, Daouidi y Ruiz Conejero y su recepción interna", Blog Una mirada crítica a las relaciones laborales [en línea] [fecha de consulta 23/01/2019], disponible en: https://ignasibeltran.com/2018/03/19/extincion-del-contrato-durante-enfermedad-o-dolencia-de-largaduracion-doctrinas-chacon-navas-danmark-daouidi-y-ruiz-conejero-y-su-recepcion-interna/.
} 
Álvarez Del CuviLlo, A., “Aspecto del trabajador y prohibición de discriminación”, Trabajo y Derecho, $\mathrm{n}^{\circ}$ 10, 2015, p. 57-80.

BAllester PAstor, M. A., "Uber saca un estudio que culpa a las mujeres de la brecha salarial”, Blog Argumentos en Derecho Laboral [en línea] [fecha de consulta 30/11/2018], disponible en: https://adriantodoli.com/2018/02/27/uber-saca-un-estudioque-culpa-a-las-mujeres-de-la-brecha-salarial/.

Beltran DE Heredia Ruiz, I., "Extinción del contrato durante enfermedad o dolencia de larga duración: Doctrinas Chacón Navas, Danmark, Daouidi y Ruiz Conejero y su recepción interna", Blog Una mirada crítica a las relaciones laborales [en línea] [fecha de consulta 23/01/2019], disponible en: https://ignasibeltran.com/2018/03/19/extinciondel-contrato-durante-enfermedad-o-dolencia-de-larga-duracion-doctrinas-chacon-navasdanmark-daouidi-y-ruiz-conejero-y-su-recepcion-internal.

Chacartegui Jávega, C., "Incidencia de nuevas TIC en la intermediación privada, el problema de la utilización de plataformas electrónicas para eludir derechos", XXIX Jornadas Catalanas de Derecho Social, Barcelona, 8 y 9 de marzo de 2018, disponible en: http://www.iuslabor.org/jornades-i-seminaris/ponencies/any-2018/.

Charro Baena, P. y San Martín Mazzucconi, C., "Decálogo jurisprudencial básico sobre igualdad y no discriminación en la relación laboral", Revista del Ministerio de Trabajo y Asuntos Sociales, ${ }^{\circ}$ Extra: Igualdad de oportunidades para todos, 2007, p. 77-120.

COMISIÓN EUROPEA, Eurobarómetro La discriminación en la UE en 2015. Resultados en España, [en línea] [fecha de consulta 28/11/2018], disponible en: http://ec.europa.eu/COMMFrontOffice/publicopinion/index.cfm/Survey/getSurveyDetai 1/instruments/SPECIAL/surveyKy/2077.

Cotino Hueso, L., "Big data e inteligencia artificial. Una aproximación a su tratamiento jurídico desde los derechos fundamentales", Dilemata, no 24, 2017, p. 131150 .

De ViCEnTE PACHÉs, F., El derecho del trabajador al respeto de su intimidad, Consejo Económico y Social, Madrid, 1998.

FABRegat Monfort, G., "La incidencia de la Ley Orgánica 3/2007, de 22 de marzo, para la igualdad efectiva de mujeres y hombres en materia de negociación colectiva. En 
especial, en los planes de igualdad”, en Romero Burillo, A.M. y RodríGuez Ordaz, C. (Coordinadoras), Trabajo, género e igualdad, Thomson Reuters Aranzadi, Cizur Menor (Navarra), 2018, p. 369-390.

FABregat Monfort, G., La discriminación de género en el acceso al mercado de trabajo, Tirant lo Blanch, Valencia, 2008.

FERnÁNDEZ Enguita, M., "El futuro digital y la desigualdad que viene", en AyALA CAÑ́n, L. Y RuIZ-Huerta CARBOnell, J. (Directores), 3er Informe sobre la desigualdad en España, Fundación Alternativas, Madrid, 2018, p. 259-278.

FERnÁNDEZ GARCÍA, A., "Aplicaciones móviles para buscar empleo: aspectos jurídicolaborales" en Todolí Signes, A. Y Hernández Bejarano, M. (Coordinadores.), Trabajo en Plataformas Digitales: innovación, Derecho y mercado, Thomson Reuters Aranzadi, Cizur Menor (Navarra), 2018.

Fernández García, A. y Ureña Martín, A., "La igualdad en el acceso al empleo, la clasificación, la formación y la promoción profesional" en ROMERO BURILLO, A.M. y RodríGuez Ordaz, C. (Coordinadoras), Trabajo, género e igualdad, Thomson Reuters Aranzadi, Cizur Menor (Navarra), 2018, p. 23-64.

GhayAD, R. y Dickens, W. T., "What Can We Learn by Disaggregating the Unemployment-Vacancy Relationship?", FRB of Boston Public Policy Brief, 2012, no 12-3, disponible en: https://papers.ssrn.com/sol3/papers.cfm?abstract_id=2285075.

Goldin, C. y Rouse, C., "Orchestrating Impartiality: The Impact of 'Blind' Auditions on Female Musicians", American Economic Review, 2000, vol. 90, n 4, p. 715-741, disponible en: DOI: 10.1257/aer.90.4.715.

GoÑI SEIN, J. L., El respeto a la esfera privada del trabajador, Civitas, Madrid, 1988.

GOODMAN, B., y FlaXMAN, S., "European Union regulations on algorithmic decisionmaking and a 'right to explanation"”, AI Magazine, vol. 38, n 3, 2017, p. 50-57.

HAYs, Guía del mercado laboral 2018, [en línea] [fecha de consulta 21/01/2019], disponible en: http://guiasalarial.hays.es/trabajador/encuestas/empresas\#pregunta81.

IKEA IBÉRICA S.A., "IKEA apuesta por el CV anónimo en sus procesos de selección para favorecer la igualdad”, Nota de prensa de 28 de abril de 2018, [en línea] [fecha de 
consulta 05/12/2018], disponible en:

https://www.ikeainfo.com/prensa/nota.php?id_nota=718.

INFOEMPLEO-ADECCO, Informe Infoempleo Adecco 2017, [en línea] [fecha de consulta 21/01/2019], disponible en: https://www.infoempleo.com/informe-infoempleo-adecco/.

Koch, A. J., D’MELlo, S. D., y SACKETT, P. R., “A meta-analysis of gender stereotypes and bias in experimental simulations of employment decision making", Journal of Applied Psychology, $\mathrm{n}^{\circ}$ 100, 2015, p. 128-161, disponible en: http://dx.doi.org/10.1037/a0036734.

Luján Alcaraz, J. y Selma Penalva, A., "Planes de igualdad", en SÁnchez Trigueros, C. (Directora), Kahale Carrillo, D. T. y Velasco Portero, T. (Coordinadores), El principio de igualdad en la negociación colectiva, Ministerio de Empleo y Seguridad Social, Madrid, 2016, p. 454-492.

Martínez Miranda, M. M., "Los retos de los principios esenciales del Derecho del Trabajo: El principio de igualdad", XXVII Jornadas Catalanas de Derecho Social, Barcelona, 17 y 18 de marzo de 2016, disponible en: http://www.iuslabor.org/jornadesi-seminaris/ponencies/any-2016/.

Mercader Uguina, J. R., El futuro del trabajo en la era de la digitalización y la robótica, Tirant lo Blanch, Valencia, 2017.

Monasterio AstobizA, A., "Ética algorítmica: implicaciones éticas de una sociedad cada vez más gobernada por algoritmos”, Dilemata, no 24, 2017, p. 185-217.

Moreno Romero, E., "Bienvenida Vera, y bienvenida toda la AI al empleo", Blog Edulcoro el empleo 2.0, [en línea], [Fecha de consulta 05/12/2018], disponible en: http://edulcoro.blogspot.com/2018/05/bienvenida-vera-y-bienvenida-toda-la-ai.html.

Moss-Racusin, C. A., Dovidio, J.F., Brescoll, V. L., Graham, M. J. y Handelsman, J., "Science faculty's subtle gender biases favor male students", Proceedings of the National Academy of Sciences, vol. 109, n 41, 2012, p. 16474-16479, disponible en: https://doi.org/10.1073/pnas.1211286109.

Noguera, I., Guerrero-Roldán, A. E, Huertas, H., Roca, R. y Baneres, D., "Enhancing the quality of online assessment with the support of an e-authentication system", 10th International Conference on Education and New Learning Technologies 
(EDULEARN'18), 2018, p. 1893-1903, disponible en: DOI: 10.21125/edulearn.2018.0546.

PÉREZ DEL Río, T., "El principio de igualdad de trato y la prohibición de discriminación por razón de sexo en el derecho Comunitario", en RuIz PÉREZ, E. (Coordinadora), Mujer y trabajo, Bomarzo, Albacete, 2003, p. 281-319.

Pontón Merino, P. y PAStOR GosÁlbez, I, "Los convenios colectivos como herramienta para alcanzar la igualdad de género en el trabajo. Estudio de caso: la industria química en Tarragona", BARATARIA Revista Castellano-Manchega de Ciencias Sociales, $\mathrm{n}^{\mathrm{o}}$ 18, 2014, p. 113-136, disponible en: DOI: http://dx.doi.org/10.20932/barataria.v0i18.47.

Preciado Domènech, C. H., El derecho a la protección de datos en el contrato de trabajo. Adaptado al nuevo Reglamento 679/2016, de 27 de abril, Thomson Reuters Aranzadi, Cizur Menor (Navarra), 2017.

Purcalla Bonilla, M. A., "Velo islámico y empleo por cuenta ajena", Blog AFLabor [en línea] [fecha de consulta 28/11/2018], disponible en: https://aflabor.wordpress.com/2017/03/28/velo-islamico-y-empleo-por-cuenta-ajenacolaboracion-de-miquel-angel-purcalla-bonilla/.

RINNE, U., "Anonymous job applications and hiring discrimination", IZA World of Labor, $\mathrm{n}^{\circ} 48,2018$, disponible en: doi: 10.15185/izawol.48.v2.

RiVAS VALLEJO, P., ¿¿Es la obesidad causa de discriminación tutelable en el ámbito laboral?”, IUSLabor, no 1, 2015, disponible en:

https://www.raco.cat/index.php/IUSLabor/article/view/288502.

Rodríguez CResPo, M. J., "Políticas activas de empleo para mejorar la inserción laboral de las mujeres: políticas públicas en retroceso y derechos indisponibles en tiempos de crisis", en SÁEz LARA, C. (Coordinadora), Igualdad de género en el trabajo: estrategias y propuestas, Ediciones Laborum, Murcia, 2016, p. 13-55.

SAITUA IRIBAR, A., "Diversidad de género como parte de la RSC y sostenibilidad en las empresas. Avances para la mejora de la divulgación de información no financiera sobre las políticas de igualdad y sus resultados", Lan Harremanak: Revista de relaciones laborales, $\mathrm{n}^{\circ} 38,2017$, p. 178-203. 
Sánchez Trigueros, C. (Directora), Kahale Carrillo, D.T. y Velasco Portero, T. (Coordinadores), El principio de igualdad en la negociación colectiva, Ministerio de Empleo y Seguridad Social, Madrid, 2016.

SIERRA HERnÁIZ, E., "El papel de los planes de igualdad en la implantación de medidas de igualdad efectiva en las empresas", Lan Harremanak: Revista de relaciones laborales, $\mathrm{n}^{\circ} 38,2017$, p. 204-228. 